\title{
Antitumor and immunomodulatory effects of low-dose 5-FU on hepatoma 22 tumor-bearing mice
}

\author{
ZHIYUN CAO ${ }^{1}$, ZHIDENG ZHANG ${ }^{2}$, ZHENGRONG HUANG ${ }^{3}$, RONGPING WANG $^{3}$, \\ AILIAN YANG ${ }^{3}$, LIANMING LIAO $^{1}$ and JIAN DU ${ }^{1,4}$

\begin{abstract}
${ }^{1}$ Fujian Academy of Integrative Medicine, Fujian University of Traditional Chinese Medicine, Fuzhou, Fujian 350108; ${ }^{3}$ Department of Integrated Chinese and Western Medicine, Fujian Provincial Cancer Hospital, Fuzhou, Fujian 350000;

${ }^{4}$ Health Check Center, The Second People's Hospital of Fujian Province, Fuzhou, Fujian 350003, P.R. China
\end{abstract} \\ ${ }^{2}$ Inspection and Quarantine Technique Centre of Fujian Entry-Exit Inspection and Quarantine Bureau, Fuzhou, Fujian 350001;
}

Received May 23, 2013; Accepted November 25, 2013

DOI: $10.3892 / \mathrm{ol} .2014 .1856$

\begin{abstract}
Low-dose 5-fluorouracil (5-FU), a widely used chemotherapeutic, has been reported to have immunomodulatory effects. This study aimed to evaluate the optimal dose of 5-FU that produces antitumor and immunomodulatory effects. In a hepatoma 22 tumor-bearing mouse model, 0, 10, 20 and $40 \mathrm{mg} / \mathrm{kg}$ 5-FU (i.p.) was administered for 10 days. Tumor weight and volume were measured, thymus index (TI) and spleen index (SI) were calculated, and the number of white blood cells (WBCs) and lymphocytes (LYs) were counted following treatment. The percentages of $\mathrm{CD}^{+}, \mathrm{CD}^{+}, \mathrm{CD}^{+}$and natural killer (NK) cells were measured by flow cytometry. In addition, the body weights of the mice were measured and the average diet consumption was calculated. Administration of 5-FU produced a potent antitumor effect in a dose-dependent manner $(\mathrm{P}<0.01)$. At 20 and $40 \mathrm{mg} / \mathrm{kg}$, a significant reduction of body weight and food consumption was observed. TI and SI decreased in the 20 - and $40-\mathrm{mg} / \mathrm{kg}$ groups $(\mathrm{P}<0.01)$ for 10 days. The number of WBCs significantly decreased in each group $(\mathrm{P}<0.01)$; however, the number of LYs only decreased in the $40-\mathrm{mg} / \mathrm{kg}$ group $(\mathrm{P}<0.01)$. Percentages of $\mathrm{CD}^{+}$and $\mathrm{CD}^{+}$cells were increased in the $10-$ and $20-\mathrm{mg} / \mathrm{kg}$ groups $(\mathrm{P}<0.01)$. Thus, $5-\mathrm{FU}$ at $10 \mathrm{mg} / \mathrm{kg}$ inhibits tumor growth while maintaining the immune function of the mice. 5-FU may exert
\end{abstract}

Correspondence to: Dr Lianming Liao, Fujian Academy of Integrative Medicine, Fujian University of Traditional Chinese Medicine, No. 1 Huatuo Road, Fuzhou, Fujian 350108, P.R. China E-mail: 1lm@fjtcm.edu.cn

Dr Jian Du, Health Check Center, The Second People's Hospital of Fujian Province, No. 282 Wusi Road, Fuzhou, Fujian 350003, P.R. China

E-mail: dujian@fjtcm.edu.cn

Abbreviations: 5-FU, 5-fluorouracil; H22, hepatoma 22; WBC, white blood cell; LY, lymphocyte; TI, thymus index; SI, spleen index; TV, tumor volume; PBS, phosphate-buffered saline

Key words: 5-FU, immunomodulatory, antitumor, mice its antitumor effect at a low dose with low toxicity and stimulate the host immune system. Future clinical trials taking into account the immunostimulatory capacity of chemotherapeutic agents are desirable for certain patients.

\section{Introduction}

Cancer patients are frequently immunologically suppressed during treatment. Chemotherapy is usually considered immunosuppressive due to its toxicity to bone marrow cells (1). However, certain chemotherapeutic agents, including leucovorin, cyclophosphamide, methotrexate and cisplatin, have been shown to activate an anticancer immune response at a low dose (2-4).

5-Fluorouracil (5-FU) is one of the most commonly used chemotherapeutics in the treatment of malignancies arising from the breast, gastrointestinal tract, head and neck (5). Over the last decades a variety of doses of 5-FU have been developed in clinical trials for the treatment of gastrointestinal tumors. These include the Mayo regimen (600 $\mathrm{mg} / \mathrm{m}^{2}$ bolus) (6), FOLFOX4 regimen $\left(400 \mathrm{mg} / \mathrm{m}^{2}\right.$ bolus plus $600 \mathrm{mg} / \mathrm{m}^{2}$ continuous infusion) (7) and Arbeitsgemeinschaft Internistische Onkologie schedule $\left(2,000-2,600 \mathrm{mg} / \mathrm{m}^{2}\right)(8)$. These regimens have been shown to produce different toxicity patterns (9). For example, single-agent bolus 5-FU administered weekly, which was in the past the standard schedule and route of administration for this drug in gastrointestinal cancer, is associated with marked myelosuppression. The commonly used 5-FU/calcium folinate regimens, depending on the doses and schedules, may produce a combination of mucositis, diarrhea and myelosuppression (10). However, low-dose (250-300 $\mathrm{mg} / \mathrm{m}^{2} /$ day) continuous infusion of 5 -FU is associated with little myelosuppression (11). In general, the incidence of grade 3-4 toxicity (mainly neutropenia, diarrhea, mucositis and hand-foot syndrome) increases with higher systemic exposure to 5-FU (12).

However, several studies have shown that patients receiving low-dose 5-FU have favorable survival rates without toxicity $(13,14)$. These studies suggest that the favorable outcome in patients receiving low-dose 5-FU may be due to its immunomodulatory effects and enhancement of the immunologic function of the host. However, whether 5-FU exerts its 
antitumor action at a low dose that enhances the host's immune function, as well as having minimal side effects, has not been reported.

In this study, we evaluated whether there was an optimal dose of 5-FU with antitumor and immunomodulatory effects, without evident side effects in hepatoma 22 (H22) tumor-bearing mice.

\section{Materials and methods}

Reagents. 5-FU (25 mg/ml) was purchased from Shanghai Amino Acids Company (Shanghai, China) and diluted to $10 \mathrm{mg} / \mathrm{ml}$ with normal saline (NS). Peridinin chlorophyll protein complex-conjugated hamster anti-mouse CD3, fluorescein isothiocyanate-conjugated rat anti-mouse CD4, phycoerythrin (PE)-conjugated rat anti-mouse CD8 and PE-conjugated rat anti-mouse CD49 were purchased from BD Biosciences (San Jose, CA, USA).

Mice. Male Institute of Cancer Research mice (body weight, 18-22 g) were purchased from the School of Basic Medical Science, Peking University (Beijing, China). The animals were maintained in a pathogen-free facility $\left(23 \pm 2^{\circ} \mathrm{C}, 55 \pm 5 \%\right.$ humidity). All procedures on treating mice were performed according to the law on Animal Care Guidelines, and the Animal Care Committee of Fujian University of Traditional Chinese Medicine (Fuzhou, China) approved the study protocols. The murine H22 cell line was from the School of Basic Medical Science, Peking University. Cells were cultured in Dulbecco's modified Eagle's medium (Gibco Laboratories, Grand Island, NY, USA) supplemented with $10 \%$ fetal bovine serum (Gibco Laboratories), penicillin and streptomycin (10,000 U/ml; Gibco Laboratories) in a humidified atmosphere with $5 \% \mathrm{CO}_{2}$ at $37^{\circ} \mathrm{C}$.

Tumor xenograft. The hepatoma model was established by subcutaneous inoculation of $\mathrm{H} 22$ cells $\left(1 \times 10^{6}\right.$ cells per mouse) into the right flank of mice. Then, $48 \mathrm{~h}$ after inoculation, mice were randomly divided into four groups $(n=6)$ as follows: Control group (NS, i.p.), $10-\mathrm{mg} / \mathrm{kg}$ group (i.p.), $20-\mathrm{mg} / \mathrm{kg}$ group (i.p.) and 40-mg/kg group (i.p.). On day 10, peripheral blood was collected from the orbital plexus and tumors were excised. The tumor volume (TV) was calculated according to the following formula: TV $\left(\mathrm{mm}^{3}\right)=\mathrm{d}^{2} \mathrm{xD} / 2$, where $\mathrm{d}$ and $\mathrm{D}$ were the shortest and longest diameters, respectively.

Food intake and body weight. Each cage of mice was provided with daily food. The following day, the remaining food was collected and weighed. The daily food intake was calculated by subtracting this value from the amount of diet provided the previous day. The well-being of the mice was monitored daily and the body weight was measured at baseline and after 10 days of treatment.

Biochemical assay. A capillary pipette containing anticoagulant [ethylene diamine tetraacetic acid (EDTA) for cell counting and heparin for flow cytometry] was inserted in the lateral canthus and blood was collected from the retroorbital sinus. A $20-\mu 1$ whole blood sample was collected and blood cells were counted using an automated Blood Cell Counter (Abbott Laboratories, Abbott Park, IL, USA).
Table I. Number of WBCs and LYs in peripheral blood of H22-bearing mice.

\begin{tabular}{lcc}
\hline Dose $(\mathrm{mg} / \mathrm{kg})$ & WBC $\left(\times 10^{9} / \mathrm{l}\right)$ & LY $\left(\times 10^{9} / 1\right)$ \\
\hline $\mathrm{NS}$ & $8.0 \pm 1.2$ & $3.5 \pm 1.1$ \\
10 & $4.6 \pm 0.5^{\mathrm{a}}$ & $3.6 \pm 0.3$ \\
20 & $4.4 \pm 0.4^{\mathrm{a}}$ & $3.5 \pm 0.4$ \\
40 & $1.1 \pm 0.4^{\mathrm{a}}$ & $0.9 \pm 0.4^{\mathrm{a}}$ \\
\hline
\end{tabular}

Dose was administered over a 10-day period. Results are presented as the mean \pm standard deviation, $n-=6$. ${ }^{a} \mathrm{P}<0.01$, compared with the NS group. NS, normal saline; WBC, white blood cell, LY, lymphocyte.

Thymus index (TI) and spleen index (SI). The thymus and spleen were collected from the mice, washed with phosphate-buffered saline (PBS) and weighed. TI and SI were calculated according to the following formulae: $\mathrm{TI}=$ thymus weight $(\mathrm{mg}) /$ body weight $(\mathrm{g}) \mathrm{x} 100 ; \mathrm{SI}=$ spleen weight (mg) / body weight (g) x100.

Assay for percentage of immune cells. Heparin-coated blood (100 $\mu \mathrm{l})$ was added to a tube and incubated with fluorochrome-conjugated antibodies, respectively, in the dark for $10 \mathrm{~min}$. The $2.5 \mu \mathrm{l}$ antibodies used included a combination of CD3/CD4, CD3/CD8 and CD3/CD49. Erythrocytes were lysed by red blood cell lysis buffer $(0.155 \mathrm{~mol} / \mathrm{l}$ ammonium chloride, $0.01 \mathrm{~mol} / 1$ potassium bicarbonate, $0.1 \mathrm{mmol} / 1$ EDTA and $1 \%$ paraformaldehyde in PBS) for $10 \mathrm{~min}$. After washing with PBS, the samples were resuspended with $500 \mu \mathrm{l}$ PBS and analyzed using a FACSCalibur ${ }^{\mathrm{TM}}$ flow cytometer with CellQuest $^{\mathrm{TM}}$ software (BD Biosciences).

Statistical analyses. Statistical analysis was performed using SPSS 16.0 (SPSS, Inc., Chicago, IL, USA). Data are presented as the mean \pm standard deviation. One-way analysis of variance was used and significant differences were analyzed by Dunnett's multiple comparison test to compare with the control group. $\mathrm{P}<0.05$ was considered to indicate a statistically significant difference.

\section{Results}

Effects of 5-FU on tumor growth in H22-bearing mice. Tumor-bearing mice were randomly divided into four groups as described in Materials and methods and treated with 5-FU for 10 days. After 10 days, tumor weights were $0.39 \pm 0.05$, $0.17 \pm 0.02,0.12 \pm 0.02$ and $0.07 \pm 0.01 \mathrm{~g}$ in the control, 10-, 20and $40-\mathrm{mg} / \mathrm{kg}$ groups, respectively, which exhibited a reduction by $56(\mathrm{P}<0.01), 69(\mathrm{P}<0.01)$ and $82 \%(\mathrm{P}<0.01)$, respectively. TV demonstrated the same tendency as tumor weight among the four groups (Fig. 1).

Food intake and body weight. We monitored the body weight at baseline and after treatment, as well as diet consumption every day, which are widely used to assess gross toxicity of a test compound. There was no statistically significant difference in body weight among the groups at baseline. Following 
Table II. Percentages of $\mathrm{CD}^{+}, \mathrm{CD}^{+}, \mathrm{CD}^{+}$and NK cells in peripheral blood of $\mathrm{H} 22$-bearing mice.

\begin{tabular}{|c|c|c|c|c|}
\hline Dose (mg/kg) & $\mathrm{CD}^{+}(\%)$ & $\mathrm{CD}^{+}(\%)$ & $\mathrm{CD}^{+}(\%)$ & NK (\%) \\
\hline NS & $48.5 \pm 3.5$ & $36.4 \pm 3.9$ & $12.1 \pm 1.6$ & $14.0 \pm 3.3$ \\
\hline 10 & $82.7 \pm 1.8^{\mathrm{a}}$ & $71.7 \pm 0.4^{\mathrm{a}}$ & $11.0 \pm 1.3$ & $6.4 \pm 2.9^{\mathrm{a}}$ \\
\hline 20 & $81.0 \pm 8.5^{\mathrm{a}}$ & $71.3 \pm 8.2^{\mathrm{a}}$ & $9.7 \pm 6.9$ & $9.9 \pm 11.2^{\mathrm{b}}$ \\
\hline 40 & $38.8 \pm 6.6^{\mathrm{a}}$ & $34.4 \pm 7.4$ & $4.4 \pm 1.8^{\mathrm{a}}$ & $12.0 \pm 3.7$ \\
\hline
\end{tabular}

Dose was administered over a 10-day period. Results are presented as the mean \pm standard deviation $(\mathrm{n}=6)$. ${ }^{\mathrm{a}} \mathrm{P}<0.01$ and ${ }^{\mathrm{b}} \mathrm{P}<0.05$, compared with the NS group. NK, natural killer; NS, normal saline.

A

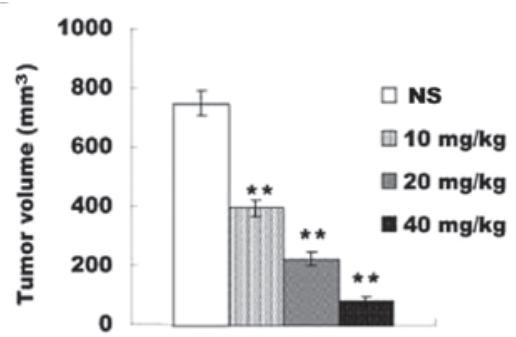

B

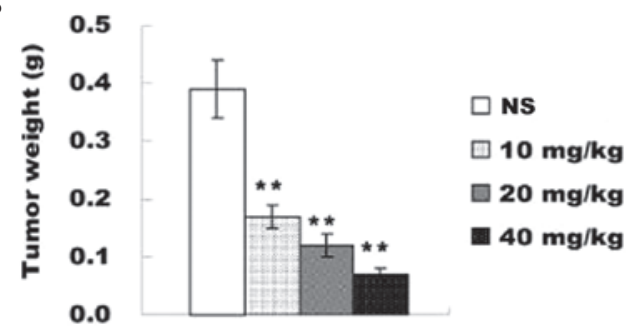

Figure 1. Effects of different doses of 5-FU on H22 solid tumor growth. H22 tumor-bearing mice were treated with NS (control group) or 5-FU (10, 20 and $40 \mathrm{mg} / \mathrm{kg}$ ). The antitumor effect of each regimen was evaluated by measuring (A) tumor volume and (B) tumor weight. The results presented are the mean \pm standard deviation $(\mathrm{n}=6){ }^{* * *} \mathrm{P}<0.01$, compared with the NS group. 5-FU, 5-fluorouracil; NS, normal saline.

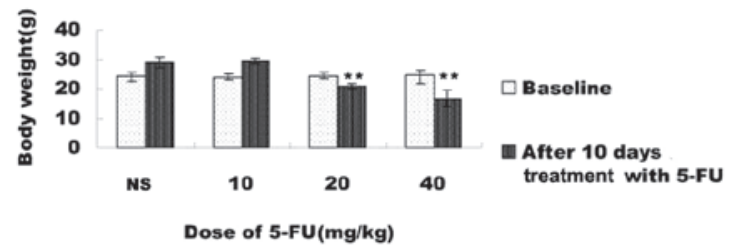

Figure 2.Effects of different doses of 5-FU on body weight.H22 tumor-bearing mice were established and treated for 10 days with different doses of 5-FU. The body weight gain was calculated after treatment for 10 days. The results presented are the mean \pm standard deviation $(n=6) .{ }^{* *} \mathrm{P}<0.01$, compared with the NS group. 5-FU, 5-fluorouracil; NS, normal saline.

treatment with 5-FU for 10 days, the body weight was similar between the control group and the $10-\mathrm{mg} / \mathrm{kg}$ group. However, body weight was significantly lower in the $20-$ and $40-\mathrm{mg} / \mathrm{kg}$ groups compared with the control group $(\mathrm{P}<0.01$; Fig. 2$)$. The average diet consumption of the control and $10-\mathrm{mg} / \mathrm{kg}$ groups were similar; however, it was smaller in the $20-$ and $40-\mathrm{mg} / \mathrm{kg}$ groups ( $\mathrm{P}<0.01$ vs. control group; Fig. 3$)$.

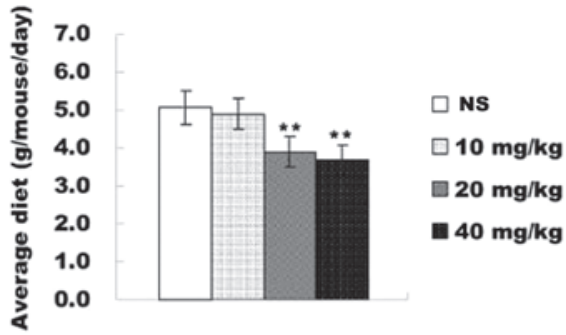

Figure 3. Effects of different doses of 5-FU on average diet. H22 tumor-bearing mice were established and treated for 10 days with different doses of 5-FU. The diet weight was measured and the average consumption per mouse is shown. The results presented are the mean \pm standard deviation $(\mathrm{n}=6){ }^{* *} \mathrm{P}<0.01$, compared with the NS group. 5-FU, 5-fluorouracil; NS normal saline.

A

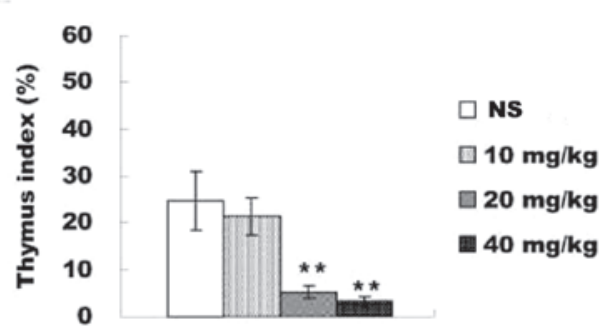

B

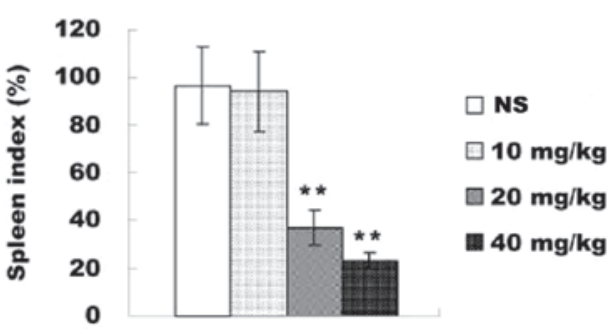

Figure 4. Effects of different doses of 5-FU on TI and SI. The thymus and spleen were washed with phosphate-buffered saline and weighed. (A) TI was calculated according to the following formula: $\mathrm{TI}=$ [thymus weight (mg) / body weight (g)] x100. (B) SI was calculated according to the following formula: $\mathrm{SI}=$ [spleen weight $(\mathrm{mg}) /$ body weight $(\mathrm{g})] \mathrm{x} 100$. The results presented are the mean \pm standard deviation $(\mathrm{n}=6)$. ${ }^{* *} \mathrm{P}<0.01$, compared with the NS group. 5-FU, 5-fluorouracil; TI, thymus index; SI, spleen index.

Effects of 5-FU on the number of WBCs. To investigate the role of 5-FU on the distribution of circulating WBCs, whole blood WBC and LY levels were counted at day 10. As shown in Table I, WBC number was decreased significantly in the 
10- $(\mathrm{P}<0.01), 20-(\mathrm{P}<0.01)$ and 40-mg/kg $(\mathrm{P}<0.01)$ groups compared with the control group. LY number was only decreased in the 40-mg/kg group $(\mathrm{P}<0.01)$.

Effects of 5-FU on percentage of LYs in peripheral blood. To evaluate the effects of 5-FU on host immune system, percentages of $\mathrm{LYs}\left[\mathrm{CD}^{+}, \mathrm{CD}^{+}, \mathrm{CD}^{+}\right.$, natural killer (NK) and B cells] were measured after mice were treated with different doses of 5-FU for 10 days. As shown in Table II, the percentages of CD3 ${ }^{+}$ and $\mathrm{CD}^{+}$cells were higher in the $10-(\mathrm{P}<0.01)$ and $20-\mathrm{mg} / \mathrm{kg}$ $(\mathrm{P}<0.01)$ groups compared with the control group. Mice in the $40 \mathrm{mg} / \mathrm{kg}$ group had the lowest percentages of $\mathrm{CD}^{+}$and $\mathrm{CD}^{+}$ cells $\left(\mathrm{P}<0.05\right.$ vs. control group). The percentage of $\mathrm{CD}^{+}$cells was only decreased in the $40-\mathrm{mg} / \mathrm{kg}$ group $(\mathrm{P}<0.01)$. However, the number of NK cells was decreased in the $10-(\mathrm{P}<0.01)$ and $20-\mathrm{mg} / \mathrm{kg}(\mathrm{P}<0.05)$ groups compared with the control group.

Effects of 5-FU on TI and SI in H22-bearing mice. We also examined the effect of 5-FU on TI and SI in H22 tumor-bearing mice. After 10 days, TI and SI decreased in the 20- $(\mathrm{P}<0.01)$ and $40-\mathrm{mg} / \mathrm{kg}(\mathrm{P}<0.01)$ groups compared with the control group (Fig. 4).

\section{Discussion}

The adverse effects of 5-FU include severe immunosuppression due to inhibition of hemotopoietic cell proliferation (13). A previous study demonstrated that low-dose chemotherapeutic drugs have a positive effect on various solid tumors. Kobayashi et al reported that low dose leucovorin plus 5-FU treated seven colorectal cancer patients for a long duration without toxicity (14). The authors further reported that low dose leucovorin plus 5-FU may improve host immunity in certain patients (15).

Our results showed that 20 and $40 \mathrm{mg} / \mathrm{kg}$ 5-FU induced a significant loss of body weight and reduction in diet consumption. Codacci-Pisanelli et al reported that 15 and $20 \mathrm{mg} / \mathrm{kg}$ caused $25 \%$ loss of weight in mice (16). Vichaya et al also reported that injection with 20 and $40 \mathrm{mg} / \mathrm{kg}$ 5-FU every other day in $\mathrm{C} 57 \mathrm{BL} / 6 \mathrm{~J}$ mice resulted in weight loss and suppressed food consumption (17). Our results are consistent with these studies.

Certain chemotherapeutics have been reported to have benefit for patients at a low dose, including cyclophosphamide (CY), methotrexate (MTX) and cisplatin (Cis). Daily oral administration of low dose CY (50 or $100 \mathrm{mg} /$ day) is effective in patients with advanced solid tumors, since $\mathrm{CY}$ is capable of not only selectively ablating circulating $\mathrm{T}$ regulatory (Treg) cells, but also recovering the function of conventional $\mathrm{T}$ and NK cells. T and Treg cells coregulate the activity of each other, which leads to the restoration of peripheral T-cell proliferation and innate killing activities $(2,18-20)$. Shen et al demonstrated that low-dose, metronomic chemotherapy with Cis $(0.6 \mathrm{mg} / \mathrm{kg} / \mathrm{day})$ dramatically inhibits tumor growth without apparent body weight loss and significant upregulation of Fas (CD95) mRNA and protein in SW480 colon cancer cells and oral cancer cell lines. It is possible for low-dose Cis to attenuate inflammatory responses by inducing Fas expression on effector T cells (21-23). We found that although 5-FU at $10 \mathrm{mg} / \mathrm{kg}$ demonstrated moderate antitumor effects, no severe side effects were observed. In addition, $10 \mathrm{mg} / \mathrm{kg} 5-\mathrm{FU}$ may enhance host immune function as indicated by increased percentages of $\mathrm{CD}^{+}$and $\mathrm{CD}^{+}$cells. A dose of $10 \mathrm{mg} / \mathrm{kg}$ for tumor-bearing mice is approximately equal to $0.83 \mathrm{mg} / \mathrm{kg}$ for cancer patients. In clinical settings, 5-FU is usually administered at $12 \mathrm{mg} / \mathrm{kg} /$ day for 4 days ( $\max , 800 \mathrm{mg} /$ day) followed by $6 \mathrm{mg} / \mathrm{kg} /$ day every other day for 4 days. Kobayashi et al reported improved immune function in cancer patients receiving low-dose 5-FU $(14,15)$.

In conclusion, our study demonstrated that improved immune function achieved by low dose 5-FU may translate into an antitumor effect. Future clinical trials are required to confirm this finding.

\section{Acknowledgements}

This study was funded by the CHEN Ke-ji Integrative Medicine Development Fund (CKJ2010020) and the International Science Joint Project of the Ministry of Science and Technology of the People's Republic of China (2008DFA32200).

\section{References}

1. Mackall CL: T-cell immunodeficiency following cytotoxic antineoplastic therapy: a review. Stem cells 18: 10-18, 2000

2. Cao Y, Zhao J, Yang Z, et al: CD4+FOXP3+ regulatory T cell depletion by low-dose cyclophosphamide prevents recurrence in patients with large condylomata acuminata after laser therapy. Clin Immunol 136: 21-29, 2010.

3. Boehm IB, Boehm GA and Bauer R. Management of cutaneous lupus erythematosus with low-dose methotrexate: indication for modulation of inflammatory mechanisms. Rheumatol Int 18: 59-62, 1998.

4. Castano AP, Mroz P, Wu MX and Hamblin MR: Photodynamic therapy plus low-dose cyclophosphamide generates antitumor immunity in a mouse model. Proc Natl Acad Sci USA 105: 5495-5500, 2008.

5. Casale F, Canaparo R, Serpe L, et al: Plasma concentrations of 5-fluorouracil and its metabolites in colon cancer patients. Pharmacol Res 50: 173-179, 2004

6. Machover D, Goldschmidt E, Chollet P, et al: Treatment of advanced colorectal and gastric adenocarcinomas with 5-fluorouracil and high-dose folinic acid. NCI Monogr 5: 193-198, 1987.

7. de Gramont A, Bosset JF, Milan C, et al: Randomized trial comparing monthly low-dose leucovorin and flourouracil bolus with bimonthly high-dose leucovorin and fluorouracil bolus plus continuous infusion for advanced colorectal cancer: a French intergroup study. J Clin Oncol 15: 808-815, 1997.

8. Schmoll HJ, Köhne CH and Lorenz M: Weekly 24h infusion of high dose (HD) 5-fluorouracil (FU24h) with or without folinic acid (FA) vs. bolus FU/FA (NCCTG/Mayo) in advanced colorectal cancer (CRC): a randomized Phase III study of the a randomized Phase III study of the EORTC GUTCCG and the AIO. Proc Am Soc Clin Oncol 19: 241a, 2000.

9. Grem JL, McAtee N, Steinberg SM, et al: A phase I study of continuous infusion 5-fluoruuracil plus calcium leucovorin in combination with $\mathrm{N}$-(phosphonoacetyl)-L aspartate in metastatic gastrointestinal adenocarcinoma. Cancer Res 53: 4828-4836, 1993.

10. Hodi FS, Catalano P, Macdonald JS, et al: Age as a factor influencing the toxicity of adjuvant chemotherapy for colorectal cancer. Pending submission, 2nd International Conference on Gastrointestinal Oncology, Cologne, Germany, 1996.

11. No authors listed: Toxicity of fluorouracil in patients with advanced colorectal cancer: effect of administration schedule and prognostic factors. Meta-Analysis Group In Cancer. J Clin Oncol 16: 3537-3541, 1998.

12. Garg MB, Sevester JC, Sakoff JA and Ackland SP: Simple liquid chromatographic method for the determination of uracil and dihydrouracil plasma levels: a potential pretreatment predictor of 5-flurouracil toxicity. J Chromatogr B Analyt Technol Biomed Life Sci 774: 223-230, 2002. 
13. Vetvicka V, Kincade PW and Witte PL: Effects of 5-fluorouracil on B lymphocyte lineage cells. J Immunol 137: 2405-2410, 1986.

14. Kobayashi R, Yoshimatsu K, Ishibashi K, Yokomizo H Umehara A, Yoshida K, Fujimoto T, Watanabe K and Ogawa K: Host immunity in colorectal cancer patients treated with low-dose Leucovorin plus 5-fluorouracil. Gan To Kagaku Ryoho 31: 1783-1785, 2004 (In Japanese).

15. Kobayashi R, Yoshimatsu K, Yokomizo H, Katsube T and Ogawa K: Low-dose chemotherapy with leucovorin plus 5-fluorouracil for colorectal cancer can maintain host immunity. Anticancer Res 27: 675-679, 2007.

16. Codacci-Pisanelli G, van der Wilt CL, Pinedo HM, Franchi F, Noordhuis P, Braakhuis B, van Laar JA and Peters GJ: Antitumour activity, toxicity and inhibition of thymidylate synthase of prolonged administration of 5-fluorouracil in mice. Eur J Cancer 31 A: 1517-1525, 1995.

17. Vichaya EG, Cook JL, Frazier MA, Young EE and Meagher MW: Modeling symptoms of chemotherapy: Bortezomib and 5-fluorouracil induce sickness in mice. Brain Behav Immun 24: 6-7, 2011.

18. Young SD, Whissell M, Noble JC, Cano PO, Lopez PG and Germond CJ: Phase II clinical trial results involving treatment with low-dose daily oral cyclophosphamide, weekly vinblastine, and rofecoxib in patients with advanced solid tumors. Clin Cancer Res 12: 3092-3098, 2006.
19. Awwad M and North RJ: Cyclophosphamide-induced immunologically mediated regression of a cyclophosphamide-resistant murine tumor: a consequence of eliminating precursor L3T4+ suppressor T-cells. Cancer Res 49: 1649-1654, 1989.

20. Berd D and Mastrangelo MJ: Effect of low dose cyclophosphamide on the immune system of cancer patients: reduction of T-suppressor function without depletion of the CD8+ subset. Cancer Res 47: 3317-3321, 1987.

21. Shen FZ, Wang J, Liang J, Mu K, Hou JY and Wang YT: Low-dose metronomic chemotherapy with cisplatin: can it suppress angiogenesis in $\mathrm{H} 22$ hepatocarcinoma cells? Int J Exp Pathol 91: 10-16, 2010.

22. Pasquier E, Kavallaris M and André N: Metronomic chemotherapy: new rationale for new directions. Nat Rev Clin Oncol 7: 455-465, 2010.

23. Zhu Q, Liu JY, Yang CM, Xu HW, Zhang AZ, Cui Y, Wang HB, Qin CY and Li YQ: Influence of antitumor drugs on the expression of Fas systemin SW480 colon cancer cells. Eur J Gastroenterol Hepatol 18: 1071-1077, 2006. 